|| ISSN(online): 2589-8698 || ISSN(print): 2589-868X || International Journal of Medical and Biomedical Studies

Available Online atwww.ijmbs.info

PubMed (National Library of Medicine ID: 101738825)

Index Copernicus Value 2018: 75.71

Original Research Article

Volume 3, Issue 7; July: 2019; Page No. 294-296

\title{
ASSESSMENT OF MAGNITUDE OF ASYMPTOMATIC AIRFLOW OBSTRUCTION
}

\section{Dr. Deepali Kamdar}

Associate Professor, Department of Respiratory Medicine, Pacific Medical College and Hospital, Udaipur

Article Info: Received 02 May 2019; Accepted 25 June 2019

DOI: https://doi.org/10.32553/ijmbs.v3i7.451

Address for Correspondence: Dr. Deepali Kamdar, Associate Professor, Department of Respiratory Medicine, Pacific Medical College and Hospital, Udaipur

Conflict of interest: Nil

\section{Abstract}

Background: Asymptomatic Airflow Obstruction causes major health problem related to lung diseases worldwide, along with stress on health care infrastructure of the country. Obstructive Airway Disease also imposes economic burden and increase the out of pocket expenditure of the patient and the country.

Material \& Methods: The present prospective study was conducted at GCS Medical College, Hospital and Research Centre, Ahmadabad from January 2016 to December 2016. A sample size of 100 was calculated at $95 \%$ confidence interval at $10 \%$ acceptable margin. Patients were enrolled from outdoor and from ward by simple random sampling. Clearance from Institutional Ethics Committee was taken before start of study. Written informed consent was taken from each study participant.

Results: In the present study, on the assessment of pulmonary function test, it was found that $70 \%$ of patient had normal PFT, $18 \%$ of patients had obstructive PFT and $12 \%$ of patients had restrictive PFT. On the assessment of obstructive airway disease by GOLD - Staging it was found that out of total study participants, $8 \%$ of patients had mild obstruction (Stage 1), $6 \%$ had moderate obstruction (Stage 2), 3\% had severe obstruction (Stage 3 ) and $1 \%$ had very severe obstruction (Stage 4)

Conclusion: there was high burden of undiagnosed asymptomatic obstructive airway disease reported among patients of different severities with males were more commonly affected than females. Therefore, use of Spirometry should be incorporate in all routine health check-ups.

Key words: Obstructive Airway Disease, Asthma, Spirometry.

\section{INTRODUCTION}

Asymptomatic Airflow Obstruction causes major health problem related to lung diseases worldwide, along with stress on health care infrastructure of the country. Obstructive Airway Disease also imposes economic burden and increase the out of pocket expenditure of the patient and the country. ${ }^{[1]}$

In previous researches it was found that obstructive Airway Disease were reported frequently and often present with complications. The most commonly seen obstructive airway diseases are COPD, Asthma, Bronchitis, Bronchiolitis and Bronchiectasis. However, majority of cases were remained undiagnosed despite of its high prevalence. A report stated that, about $60 \%$ cases of chronic obstructive pulmonary disease were remain undiagnosed. ${ }^{[2]}$

In current scenario, only symptomatic patients visited to healthcare facilities for spirometry test, whereas patients with no symptoms were ignored. ${ }^{[3]}$ in various studies it was reported that less than $10 \%$ of cases who were screened by spirometry had severe or very severe obstructive Airway Disease. ${ }^{[4]}$ There were very few researches conducted to find out the undiagnosed airflow obstruction, and limited data is available for therapeutic effectiveness and the role of programs for detecting undiagnosed airflow obstruction. ${ }^{[5]}$ however, prevalence of airflow obstruction with respiratory function was well documented. ${ }^{[6]}$ Present study was conducted to assess the prevalence of asymptomatic airflow obstruction.

\section{MATERIALS \& METHODS}

The present prospective study was conducted at GCS Medical College, Hospital and Research Centre, Ahmadabad from January 2016 to December 2016. A sample size of 100 was calculated at $95 \%$ confidence interval at $10 \%$ acceptable margin of error by epi info software version 7.2. Patients were enrolled from outdoor and from ward by simple random sampling. Clearance from Institutional Ethics Committee was 
taken before start of study. Written informed consent was taken from each study participant.

The data were collected by detailed history, general physical and clinical examination from each patient after taking the written consent. Patients with not previously diagnosed Obstructive Airway disease and patients with no evidence of any physical disease were included in the study. Patients with previously diagnosed Obstructive Airway Disease, patients presenting with symptoms of Obstructive Airflow Obstruction and patients who were unable to perform Spirometry were excluded from present study. All the enrolled study participants were subjected to routine lab investigations and Spirometry (As per the ATS guidelines).

Data analysis was carried out using SPSS v22. All tests were done at alpha (level significance) of $5 \%$; means a significant association present if $p$ value was less than 0.05 .

\section{RESULTS}

In the present study, we enrolled 100 asymptomatic patients of obstructive airway disease. Out of the total study participants $26 \%$ were females and $74 \%$ were males. The mean age of males in study population was 51.28 years and mean age of females in study population was 48.62 years. Out of the total study participants, majority of patients were belonging to age group of 50 to 60years of age i.e., $42.6 \%$. on the assessment of pulmonary function test, it was found that $70 \%$ of patient had normal PFT, $18 \%$ of patients had obstructive PFT and $12 \%$ of patients had restrictive PFT. (Table 1)

Table 1: Distribution of Airflow obstruction

\begin{tabular}{|l|l|}
\hline Pulmonary function test & No. of Patients (\%) \\
\hline Normal PFT & $70 \%$ \\
\hline Obstructive PFT & $18 \%$ \\
\hline Restrictive PFT & $12 \%$ \\
\hline
\end{tabular}

In the present study, on the assessment of obstructive airway disease by GOLD - Staging it was found that out of total study participants, $8 \%$ of patients had mild obstruction (Stage 1), 6\% had moderate obstruction (Stage 2), 3\% had severe obstruction (Stage 3 ) and $1 \%$ had very severe obstruction (Stage 4).(Table-2)
Table 2: Prevalence of Severity of AO

\begin{tabular}{|l|l|}
\hline Obstructive Airway Disease & No. of Patients (\%) \\
\hline Mild & $8 \%$ \\
\hline Moderate & $6 \%$ \\
\hline Severe & $3 \%$ \\
\hline Very severe & $1 \%$ \\
\hline
\end{tabular}

\section{DISCUSSION}

In the present study, we enrolled 100 asymptomatic patients of obstructive airway disease. Out of the total study participants $26 \%$ were females and $74 \%$ were males. The mean age of males in study population was 51.28 years and mean age of females in study population was 48.62 years. Out of the total study participants, majority of patients were belonging to age group of 50 to 60years of age i.e., $42.6 \%$. on the assessment of pulmonary function test, it was found that $70 \%$ of patient had normal PFT, $18 \%$ of patients had obstructive PFT and $12 \%$ of patients had restrictive PFT. Similar results were obtained in a study conducted by David B Coultas et al among patients for asymptomatic obstructive airway disease and found that the overall prevalence of undiagnosed airflow obstruction was $12 \%$ and they reported males were more commonly affected than females. ${ }^{[7]}$ Similar results were obtained in a study conducted by Miravitlles $\mathrm{M}$ et al among patients for asymptomatic obstructive airway disease and found that the overall prevalence of undiagnosed airflow obstruction was $11 \%$ and they reported males were more commonly affected than females. ${ }^{[8]}$

Similar results were obtained in a study conducted by Dickinson JA et al among general population for asymptomatic obstructive airway disease and found that the overall prevalence of undiagnosed airflow obstruction was $9 \%$ and they also reported males were more commonly affected than females. ${ }^{[9]}$ Similar results were obtained in a study conducted by Chol Shin et al among patients for asymptomatic obstructive airway disease and found that the overall prevalence of undiagnosed airflow obstruction was $12 \%$ and they reported males were more commonly affected than females. ${ }^{[10]}$ 
In the present study, on the assessment of obstructive airway disease by GOLD - Staging it was found that out of total study participants, $8 \%$ of patients had mild obstruction (Stage 1), 6\% had moderate obstruction (Stage 2), 3\% had severe obstruction (Stage 3) and $1 \%$ had very severe obstruction (Stage 4). Similar results were obtained in a study conducted by Chol Shin et al among patients for asymptomatic obstructive airway disease and found nearly similar result to the present study. ${ }^{[0]}$ Similar results were obtained in a study conducted by Roeland $\mathrm{MM}$ et al among patients for asymptomatic obstructive airway disease and found that out of 702 patients of asymptomatic obstructive airway disease they reported 210 (29.9\%) patients had mild airflow obstruction (GOLD stage 1 ) and $25.9 \%$ patients had moderate airflow obstruction (GOLD stage 2). ${ }^{[11]}$

\section{CONCLUSION}

We concluded from the present study that there was high burden of undiagnosed asymptomatic obstructive airway disease reported among patients of different severities with males were more commonly affected than females. Therefore, use of Spirometry should be incorporate in all routine health check-ups.

\section{REFERENCES}

1. Pleasants RA, Riley IL, Mannino DM. Defining and targeting health disparities in chronic obstructive pulmonary disease. Int J Chron Obstruct Pulmon Dis [Internet]. 2016;11:2475-96. Available from: http://www.ncbi.nlm.nih.gov/pubmed/27785005

2. Athanazio R. Airway disease: similarities and differences between asthma, COPD and bronchiectasis. Clinics (Sao Paulo) [Internet]. 2012 Nov;67(11):1335-43. Available from: http://www.ncbi.nlm.nih.gov/pubmed/23184213

3. Lopez-Campos JL, Alcazar B. Evaluation of symptomatic patients without airflow obstruction: back to the future. J Thorac Dis [Internet]. 2016 Dec;8(12):E1657-60. Available from: http://www.ncbi.nlm.nih.gov/pubmed/28149607

4. Johns DP, Walters JAE, Walters EH. Diagnosis and early detection of COPD using spirometry. J Thorac Dis [Internet]. 2014 Nov;6(11):1557-69. Available from:

http://www.ncbi.nlm.nih.gov/pubmed/25478197

5. Bailey KL. The importance of the assessment of pulmonary function in COPD. Med Clin North Am [Internet]. 2012 Jul;96(4):745-52. Available from: http://www.ncbi.nlm.nih.gov/pubmed/22793942

6. Halbert RJ, Natoli JL, Gano A, Badamgarav E, Buist AS, Mannino DM. Global burden of COPD: systematic review and meta-analysis. Eur Respir J [Internet]. 2006 Sep 1;28(3):523-32. Available from: http://www.ncbi.nlm.nih.gov/pubmed/16611654

7. Coultas DB, Mapel D, Gagnon R, Lydick EVA. The health impact of undiagnosed airflow obstruction in a national sample of United States adults. Am J Respir Crit Care Med. 2001;164(3):372-7.

8. Miravitlles M, Soriano JB, Garcia-Rio F, Munoz L, Duran-Tauleria E, Sanchez $G$, et al. Prevalence of COPD in Spain: impact of undiagnosed COPD on quality of life and daily life activities. Thorax [Internet]. 2009 Oct 1;64(10):863-8. Available from: http://www.ncbi.nlm.nih.gov/pubmed/19553233

9. Dickinson JA, Meaker $M$, Searle $M$, Ratcliffe $G$. Screening older patients for obstructive airways disease in a semi-rural practice. Thorax [Internet]. 1999 Jun;54(6):501-5. Available from: http://www.ncbi.nlm.nih.gov/pubmed/10335003

10. Shin C, Lee S, Abbott RD, Je HK, Sang YL, Kwang HI, et al. Respiratory symptoms and undiagnosed airflow obstruction in middle-aged adults: The Korean Health and Genome Study. Chest [Internet]. 2004;126(4):1234-40. Available from: http://dx.doi.org/10.1378/chest.126.4.1234

11. Geijer RM, Sachs AP, Hoes AW, Salomé PL, Lammers J-WJ, Verheij TJ. Prevalence of undetected persistent airflow obstruction in male smokers 40-65 years old. Fam Pract [Internet]. 2005 Oct 1;22(5):485-9. Available from: http://academic.oup.com/fampra/ article/ 22/5/485/609107/Prevalence-of-undetectedpersistent-airflow 